\title{
Dental Caries Experience and Use of Dental Services among Female Students of Garrison School
}

\author{
Bilal Abdul Qayum Mirza1 \\ Fareed Ahmad ${ }^{2}$ \\ Muhammad Nasir Saleem ${ }^{3}$
}

\author{
BDS, MPhil \\ BDS, MCPS \\ BDS, FCPS
}

\begin{abstract}
:
BACKGROUND: Dental caries is considered the single most common chronic childhood disease. Apart from the cariogenic substrates some socio-demographic and behavioral indicators responsible for an increased caries experience include; poor oral hygiene, inadequate tooth-brushing habits, gender, frequency and timing of consumption of sugarcontaining drinks and frequency of dental visits. The purpose of the study was to evaluate dental caries experience and the use of dental services by female students with from Garrison schools of Lahore. The study was carried out at ten Garrison public schools located in the Cantonment area of Lahore, Pakistan.
\end{abstract}

METHODOLOGY: A total of 5,538 female students often Garrison public schools from playgroup to grade 10 were included in this analytical cross sectional study. The data gathered included demographic, DMFT score and frequency of dental visits. Six calibrated dentists examined the students in natural light. The students were seated on a chair and orally examined using mirror tweezer and probe. A DMFT proforma was filled per WHO criteria for assessing dental caries. Mean age and DMFT was calculated from the sample. Paired T test was used to determine the significance between DMFT and Dental visits.

RESULTS: The total number of students were 5,538 and the average age for the sample was $8.81 \pm 2.88$.The mean DMFT score was $2.48 \pm 3.09$ for the sample. Majority $(\mathrm{n}=4651,83.7 \%)$ of the female students never went to the dentist. Only few $(n=321,5.8 \%)$ of the students visited the dentist in the past six months.

CONCLUSION: The female students of Garrison public school were found to have a high caries experience. The use of dental services was poor.

KEYWORDS: Prevalence of caries, dental visits, oral examination.

HOW TO CITE: Mirza BAQ, Ahmad F, Saleem MN. Dental Caries Experience and Use of Dental Services among Female Students of Garrison School. J Pak Dent Assoc 2017; 26(1): 10-14

Received: 15 December 2016, Accepted: 24 March 2017

\section{INTRODUCTION}

$\mathrm{D}$ ental caries is considered the single most common chronic childhood disease. The amount, consistency and frequency of sugar intake is considered a very important causative agent for caries., ${ }^{1,2}$ Sticky foods remain on tooth surface for longer time and are harmful.

${ }^{1}$ Associate Professor, Department Community \& Preventive Dentistry, Institute of Dentistry, CMH Lahore Medical College. Pakistan

${ }^{2}$ Assistant Professor, Department of Oral Surgery, Institute of Dentistry, CMH Lahore Medical College. Pakistan

${ }^{3}$ Associate Professor, Department of Operative Dentistry, Institute of Dentistry, CMH Lahore Medical College. Pakistan

Corresponding author: "Dr. Bilal Abdul Qayum Mirza" < bilal_abdul_qayum@hotmail.com >
Carbohydrates in an adherent solid form are more cariogenic than their soluble state. ${ }^{3}$ In addition to these, some sociodemographic and behavioral indicators responsible for an increased caries experience include; poor oral hygiene, inadequate tooth-brushing habits, increasing age, gender, frequency and timing of consumption of sugar-containing drinks, frequency of dental visits are also common factors ${ }^{4}$. In Pakistan WHO global data has shown an increase in DMFT of 12 years old children from 0.9 to $1.38 .{ }^{5}$

Early visit of the child to the dental clinic is considered the corner stone of the prevention programs. It is widely accepted that the timing of dental visits is important in preventing the onset and progression of dental caries. ${ }^{6}$ An early dental visit makes it possible for interceptive interventions 


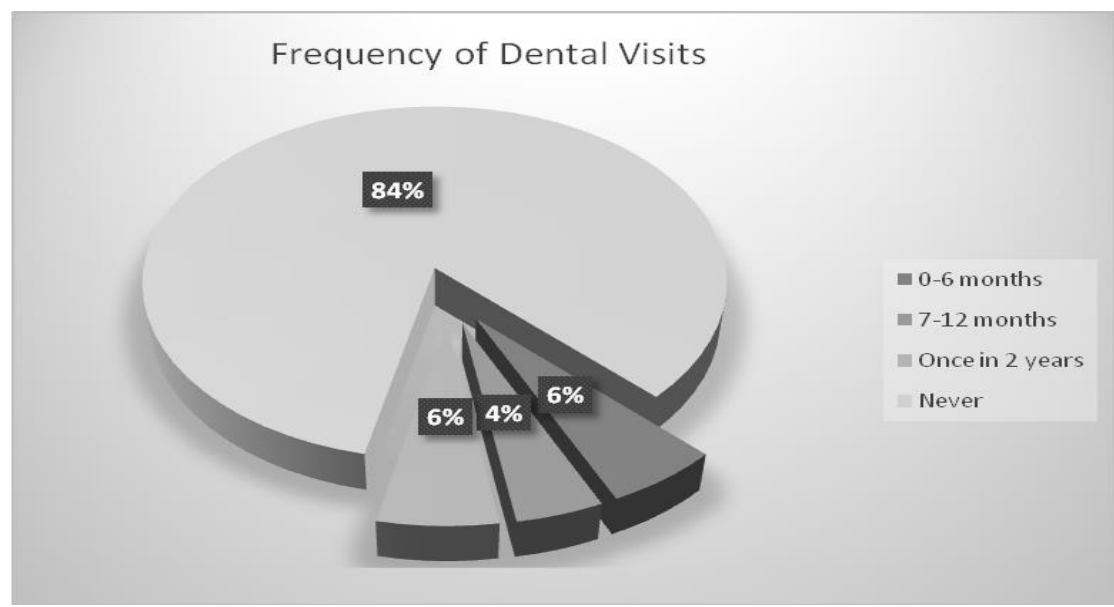

Fig. (1): Frequency of dental visits.

aimed at arresting the progression of caries lesions. A careful dental examination is not possible in very young children, but an inspection of the teeth and gingivae is often possible at one year of age, and has been advocated by a recent Nordic consensus conference. ${ }^{7}$

There is scarcity of data available which would highlight the dental caries experience and use of dental services among female students and for this reason this study was undertaken.

\section{METHODOLOGY}

The sample of this analytical cross sectional study was female students ranging from playgroup to grade 10. A total of 5,538 female students often Garrison public schools from playgroup to grade 10 were included in the study. These schools are located in the Cantonment area of Lahore, Pakistan. The data gathered included demographic, DMFT score and frequency of dental visits. Prior to the study, the consent was sought from the parents' of the students and the ethical approval for this study was given by IRC (institutional research committee) of Institute of Dentistry CMH Medical College. Six calibrated dentists examined the students in natural light. The students were seated on a chair and orally examined using mirror tweezer and probe. A DMFT proforma was filled according to WHO criteria for assessing dental caries ${ }^{8}$.

\section{Inclusion Criteria}

- All female students attending the schools from playgroup to grade 10 .

- Only students' whose parents provided consent were examined.

\section{Exclusion Criteria}

- Mentally handicapped children.

All the students examined were given oral hygiene instructions and demonstrated proper brushing technique.

The data were analyzed using SPSS v.24.

\section{Statistical Analysis}

Mean age and DMFT was calculated from the sample. The dental visits were grouped into four categories (0-6 months, 7-12 months, once in 2 years, Never). Chi test was used to analyse association between DMFT and no of dental visits. Statistical significance was set at 0.05 or below.

\section{RESULTS}

The total number of students were 5,538 and the average age for the sample was $8.81 \pm 2.88$.Fig. (1) shows the frequency of dental visits. It was observed that a majority (84\%) never visited the dentist. Only $6 \%$ of the female students visited the dentist in the past 6 months.

Fig. (2) represents the frequency of students with caries experience. Fig. (3) shows the distribution of DMFT with age among the female students. Table 1 highlights mean values of study variables.

\section{DISCUSSION}

Dental caries is a major health dilemma in underdeveloped countries and it influences $60-90 \%$ of school going children. ${ }^{9}$ In Pakistan oral health has had low priority in the health activities, which has resulted in large 


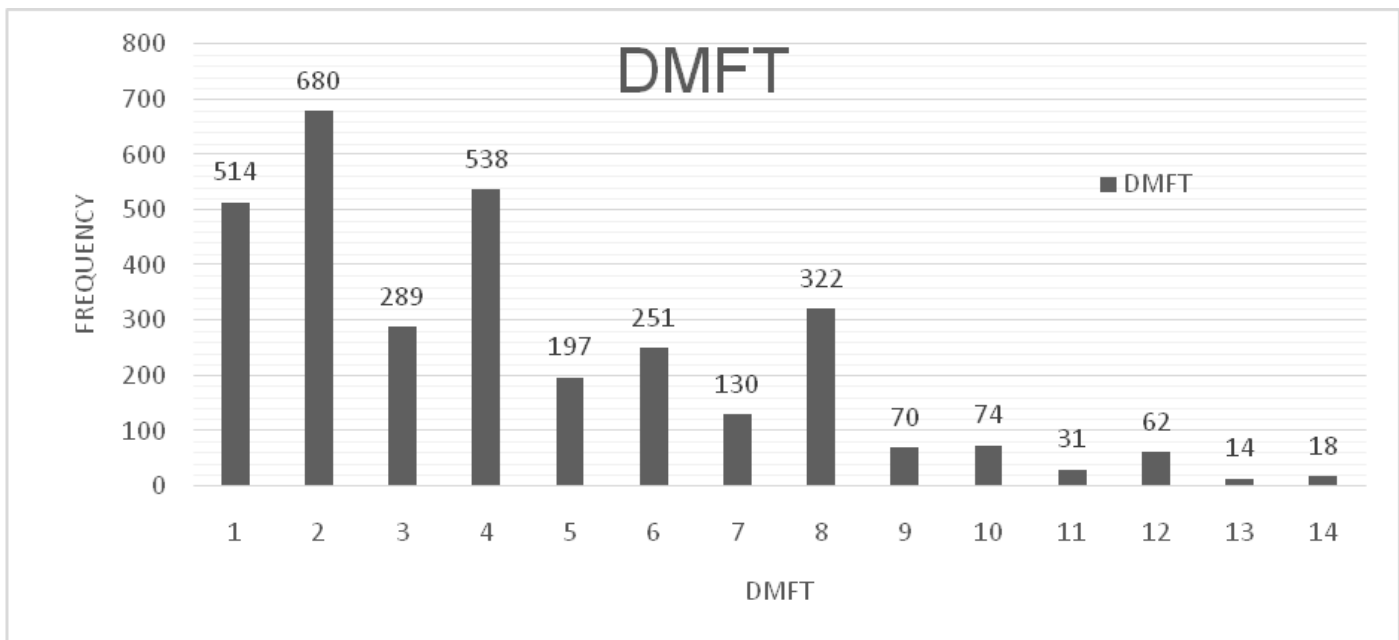

Fig. (2). Shows frequency of DMFT in students $(\mathrm{n}=3190)$.

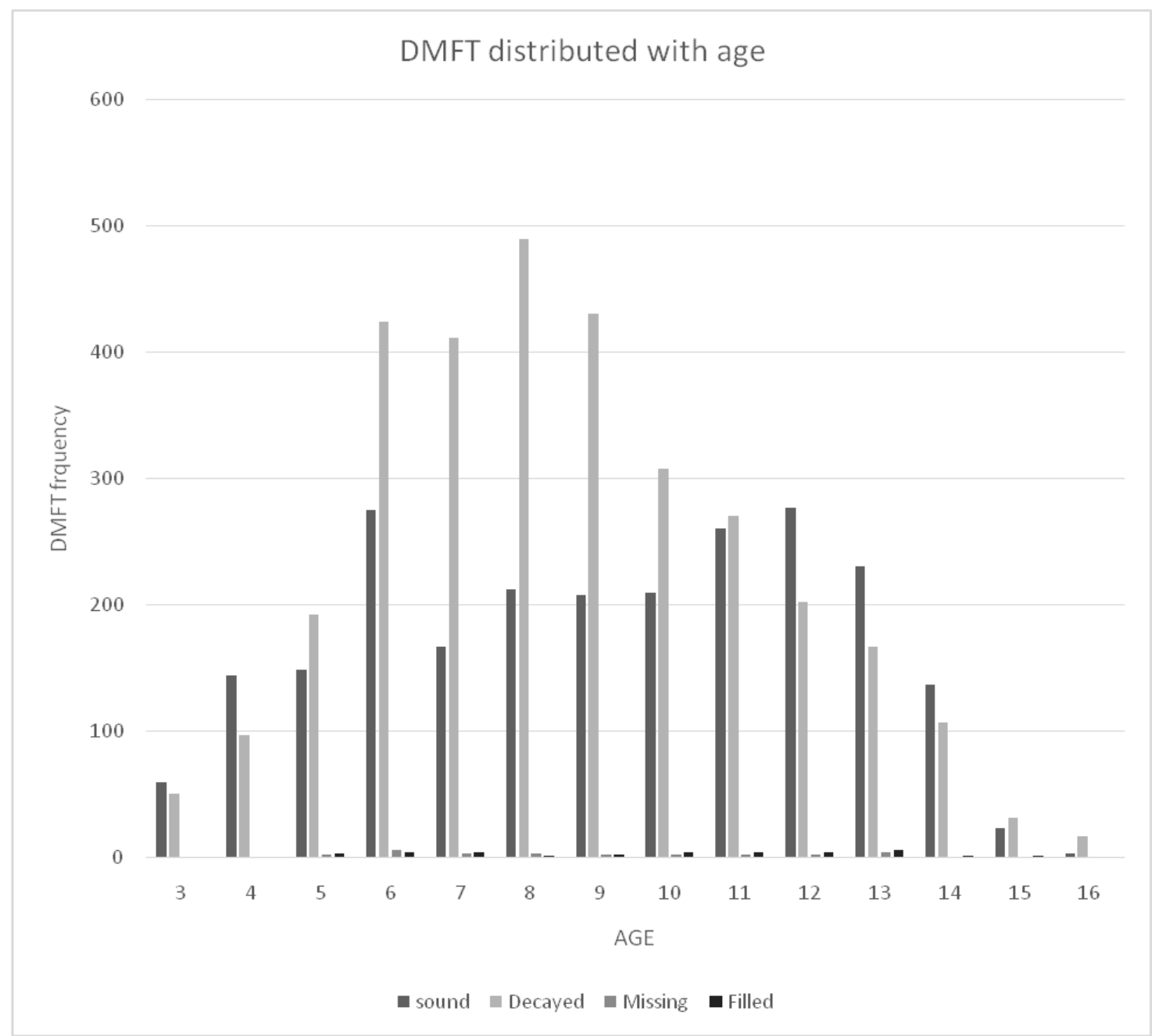

Fig. (3). Shows the distribution of DMFT with age. 
Table 1. Mean Values of study variables.

\begin{tabular}{|c|c|}
\hline Mean Age & $8.81 \pm 2.88$ \\
\hline Mean DMFT & $2.48 \pm 3.09$ \\
\hline Mean Decayed & $2.44 \pm 3.03$ \\
\hline Mean Missing & $0.01 \pm 0.15$ \\
\hline Mean Filled & $0.01 \pm 0.16$ \\
\hline$\chi^{2}$ DMFT with Dental visits & $\mathrm{P}=0.000$ \\
\hline
\end{tabular}

unfulfilled needs of the population and over $90 \%$ of all oral diseases remain untreated ${ }^{10}$. The main objective of this study was to find out the progression of dental caries and its association with dental visits. Our results suggest a strong relationship between number of visits and DMFT $(\mathrm{p}=0.000)$. The study also revealed that the mean DMFT score of $2.48 \pm$ 3.09 for female students. This also highlights the severity showing $57.6 \%(3,190)$ of the students with DMFT score of 1 or above. Out of these two third of the students $(63.35 \%)$ had up to a DMFT score of 4. Figures like these are alarmingly high for a sample with a mean age of $8.81 \pm 2.88$. These scores are attributed mainly due to decay component of DMFT, with missing and filled teeth having a negligible contribution. These figures are higher than urban mean DMFT score of $2.26 .{ }^{10}$ Reasons might include students belonging to a lower socioeconomic status, high intake of sugary diet or fewer dental visits. ${ }^{11}$ Usually food available in majority of the schools' cafeteria have high sugar content in confectionaries and fizzy drinks. Students are more than inclined to consume these due to lack of awareness or better taste.

The results suggest that all students with exception of a few have 2.48 teeth which are carious. These are extremely high figures. The level of untreated caries leads to pain, discomfort and drop in the quality of life. The students also develop low self-esteem issues in the society along with average school days missed due to dental problems. ${ }^{12}$

Instead of letting the caries progress, a timely treatment is required. When asked about the frequency of visit to the dentist, it was seen that $84 \%$ of the students never went to the dentist. The ones who went either got extraction done or had fillings which had recurrent caries. Some of the reasons for not getting teeth checked on time, could include cost of the treatment, fear of going to the dentist ortiming of the dentists' appointment availability. And we recommend a follow-up study to ascertain the association of causes mentioned.

JPDA Vol. 26 No. 01 Jan-Mar 2017
The high cost factor can be addressed by the government to start a fully funded/subsidized dental health care program for school going children which liaisons with the local hospital. Unfortunately no such initiative has been taken by the government.

The fear is also an important factor which refrains the children to go to the dentist. This can be dealt with by periodically educating the students and discussing their fears. Parents should also be educated in this regard that they shouldn't put innate fear of needles in child's mind or put the fear of needles if the child disobeys the parent. This causes the child to be petrified of going to the dentist and hence doesn't get treatment in time.

This study points the young female students have very high caries level and on top of that timely dentists' visits are not attained which affects their quality of life and eventually their studies due to sickness. ${ }^{12}$

\section{RECOMMENDATIONS}

- The government should sponsor a dental health care plan where students can get treatment at a subsidized rate; if not fully funded; at the school premises or liaison with the nearest tertiary care hospital.

- The students along with their parents should be encouraged to get their teeth examined every six months.

- The parents should be educated about dental health issues and dental visits so they can get their child's teeth treated accordingly.

\section{CONCLUSION}

The female students of Garrison public school were found to have a high caries experience. The use of dental services was poor.

\section{REFERENCES}

1. Lingstrom P, Van Houte J, Kashket S. Food starches and dental caries. Crit Rev Oral Biol Med 2000; 11: 366-80.

2. Saravanan S, Madivanan I, Subashini B, Felix JW. Prevalence pattern of dental caries in the primary dentition among school children. Ind J Dent Res 2005; 16: 140 .

3. Decker RT, Loveren CV. Sugar and dental caries. Am J Clin Nutr 2003; 78: 881-92. 
4. Declerck D, Leroy R, Martens L, Lesaffre E, GarciaZattera MJ, Broucke VS, Debyser M, Hoppenbrouwers $\mathrm{K}$ : Factors associated with prevalence and severity of caries experience in preschool children. Community Dent Oral Epidemiol. 2008, 36: 168-78.

5. Bratthall D. Estimation of global DMFT for 12-yearolds in 2004. Int Dent J. 200; 55: 370-72.

6. American academy of pediatric dentistry. Reference. Manual 2006-07. Pediatric dent 2007;28:17-19.

7. Hagoson a, falk m, johansson s. Consensus conference on caries in the primary dentition and its clinical management. Stockholm: gothia, 2002:86.

8. World health organization (who). Oral health surveys: basic methods. 5th edition. Geneva, Switzerland: who. 2013.
9. AsgharA, Shama A, Seema S. Caries prevalence among school children age 6-14 years in Gadap Town Karachi in relation to the awareness of their parents toward oral health. Pak oral dent j 2013;33: 354-58.

10. Oral health in Pakistan: A situation analysis .Ministry of health/who publication; Govt of Pakistan 2004

11. Hawa S Mbawalla, Joyce R Masalu, and Anne $\mathrm{N}$ Åstrøm. Socio-demographic and behavioural correlates of oral hygiene status and oral health related quality of life, the Limpopo - Arusha school health project (LASH): A cross-sectional study. BMC Pediatr. 2010; 10: 87.

12. Jackson S.L., William F.V.Jr, Jonathan B.K.,Bhavna T.P, Jessica Y. L,.Impact of Poor Oral Health on Children's School Attendance and Performance. Am J Public Health. 2011; 101: 1900-6. 